\title{
Efeitos da transfusão de sangue total fresco ou armazenado sobre a coagulação em caprinos
}

Nayanna Brunna da Silva Fonseca", Jucélio da Silva Gameleira, Jerson Marques Cavalcante, Aluisio de Souza Neto, Estela Ivone Borges Lemos, Francisco Fernandes Feitoza Neto, Aline Cavalcante Costa, Rodolfo Gurgel Vale, Rejane dos Santos Sousa, Raimundo Alves Barrêto Júnior.

Universidade Federal Rural do Semi-Árido (UFERSA), Mossoró, RN, Brasil

*Autor correspondente

e-mail: nayanna_brunna@yahoo.com.br

\section{Resumo}

A terapia transfusional possui grande relevância na medicina veterinária, mas é necessário considerar possíveis alterações pós-transfusionais na eficiência das reações de coagulação. Desta forma, o presente trabalho teve como objetivo avaliar os efeitos da transfusão de sangue total fresco ou armazenado sobre a via intrínseca e extrínseca da coagulação em caprinos, através da realização dos testes Tempo de Protrombina (TP) e Tempo de Tromboplastina parcial ativada (TTPA). Foram utilizados 18 caprinos hígidos, adultos, os quais foram submetidos à indução de anemia e, seis horas após, receberam transfusão de sangue total armazenado em bolsas CPDA-1 de acordo com os grupos experimentais: G0 (recebeu sangue fresco); e G15 e G35 (receberam sangue armazenado por 15 e 35 dias, respectivamente). As bolsas do G15 e G35 foram mantidas sob refrigeração a uma temperatura entre $2^{\circ}$ e $6^{\circ} \mathrm{C}$ imediatamente após a coleta, e foram homogeneizadas diariamente durante o decorrer do armazenamento. Amostras de sangue total foram colhidas em tubos a vácuo contendo citrato de sódio nos seguintes momentos: antes da indução da anemia (TC0); 6 horas após indução e antes de transfusão (TC1); 1, 6, 12, 24 e 96 horas (T1, T6, T12, T24 e T96, respectivamente) e 8, 16 e 32 dias (T8d, T16d, T32d, respectivamente) após a transfusão. Os testes de TP e TTPA foram realizados em aparelho Coagulômetro Max Clot de 4 canais (MedMax, Brasil) utilizando

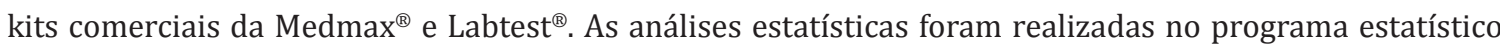
GRAPHPAD PRISM 5.0, adotando-se nível de significância de 5 \%. A avaliação da coagulação revelou maior TP no no T1 do G15; T12 do G15 e G35; e T16d do G35. O TTPA não diferiu entre os grupos estudados. Esses resultados sugerem que o sangue armazenado provocou alterações na coagulação, aumentando o TP nos animais que receberam sangue conservado. Porém, essas alterações não possuem significado clínico, pois os valores de TP e TTPA obtidos nesse estudo ficaram dentro dos valores de referência para a espécie $(25,4 \pm$ 5,69 segundos e 39,5 \pm 8,92 segundos, respectivamente). Portanto, a transfusão de sangue homólogo fresco 
ou armazenado por até 35 dias, conforme realizada nesse estudo, não afetou a via intrínseca e extrínseca do sistema de coagulação em caprinos. 